\title{
Epstein-Barr virus-associated post-transplant lymphoproliferative disorders: beyond chemotherapy treatment
}

\author{
Sanam Shahid, Susan E. Prockop \\ Department of Pediatrics, Memorial Sloan Kettering Cancer Center, New York, NY 10065, USA. \\ Correspondence to: Dr. Susan E. Prockop, Department of Pediatrics, Memorial Sloan Kettering Cancer Center, 1275 York \\ Avenue, New Yok, NY 10065, USA. E-mail: prockops@mskcc.org \\ How to cite this article: Shahid S, Prockop SE. Epstein-Barr virus-associated post-transplant lymphoproliferative disorders: \\ beyond chemotherapy treatment. Cancer Drug Resist 2021;4:646-64. https://dx.doi.org/10.20517/cdr.2021.34
}

Received: 14 Apr 2021 First Decision: 6 May 2021 Revised: 10 May 2021 Accepted: 19 May 2021 Available online: 6 Jun 2021

Academic Editor: Godefridus J. Peters Copy Editor: Xi-Jun Chen Production Editor: Xi-Jun Chen

\begin{abstract}
Post-transplant lymphoproliferative disorder (PTLD) is a rare but life-threatening complication of both allogeneic solid organ (SOT) and hematopoietic cell transplantation (HCT). The histology of PTLD ranges from benign polyclonal lymphoproliferation to a lesion indistinguishable from classic monoclonal lymphoma. Most commonly, PTLDs are Epstein-Barr virus (EBV) positive and result from loss of immune surveillance over EBV. Treatment for PTLD differs from the treatment for typical non-Hodgkin lymphoma because prognostic factors are different, resistance to treatment is unique, and there are specific concerns for organ toxicity. While recipients of HCT have a limited time during which they are at risk for this complication, recipients of SOT have a lifelong requirement for immunosuppression, so approaches that limit compromising or help restore immune surveillance are of high interest. Furthermore, while EBV-positive and EBV-negative PTLDs are not intrinsically resistant to chemotherapy, the poor tolerance of chemotherapy in the post-transplant setting makes it essential to minimize potential treatment-related toxicities and explore alternative treatment algorithms. Therefore, reduced-toxicity approaches such as single-agent CD20 monoclonal antibodies or bortezomib, reduced dosing of standard chemotherapeutic agents, and non-chemotherapy-based approaches such as cytotoxic T cells have all been explored. Here, we review the chemotherapy and non-chemotherapy treatment landscape for PTLD.
\end{abstract}


Keywords: Post-transplant lymphoproliferative disease, PTLD, Epstein-Barr virus, EBV, rituximab, CD20 monoclonal antibody, immunotherapy, chemoimmunotherapy, EBV-specific cytotoxic T lymphocytes, EBV CTLs

\section{INTRODUCTION}

Post-transplant lymphoproliferative disorder (PTLD) is a life-threatening complication of allogeneic solid organ (SOT) and hematopoietic cell (HCT) transplantation. PTLD encompasses a range of histopathology of abnormal lymphoid proliferations that occur in the context of defective immune surveillance experienced during and after transplant ${ }^{[1]}$. In the SOT setting, PTLD is most often derived from recipient lymphoid cells, while PTLD following HCT is almost exclusively of donor origin ${ }^{[2,3]}$. After HCT and early after SOT, the majority of PTLDs are driven by latency programs of Epstein-Barr virus (EBV) and reflect the requirement for active immune surveillance of EBV. PTLD developing after HCT is usually a high-grade monomorphic diffuse large B-cell lymphoma (DLBCL). These EBV-positive PTLDs are characterized by EBV-driven immortalization of B cells (and rarely T cells). Protection from EBV-positive PTLD in immune competent individuals is maintained by surveillance by cytotoxic $\mathrm{T}$ lymphocytes (CTLs) recognizing $\mathrm{EBV}^{[4]}$. A significant amount of immunologic energy is required to control EBV as these CTLs circulate at high frequency in normal EBV-immune individual ${ }^{[5]}$. In HCT recipients, the risk of PTLD resolves after reconstitution of donor-derived immunity, whereas in recipients of SOT long-term immunosuppression translates into a long-term risk of both EBV-positive and EBV-negative PTLD - ranging in histology from benign lymphoid hypertrophy to aggressive lymphoma. Overall, PTLD after SOT has a bimodal incidence with "early" PTLD developing within a year of transplantation and being nearly uniformly EBV-positive, and while there is a second peak of "late" more commonly EBV-negative PTLD five-to-ten years after transplant, it is increasingly evident that the risk of PTLD continues for as long as the patient remains on immunosuppression ${ }^{[1,6]}$. In both settings, the incidence of EBV-positive PTLD is relatively low but carries significant risk of morbidity and mortality with 2-year survival in the SOT setting as low as $50 \%{ }^{[6]}$ and as low as $10 \%$ after failure to respond to initial therapy ${ }^{[7,8]}$, as discussed in more detail later in this review. Similarly, recipients of HCT with EBV-positive PTLD that is refractory to initial therapy have dismal survival chances with median overall survival (OS) of just 1.7 months $^{[0]}$. Restoration of EBV-directed immunity to achieve durable control of EBV should be a goal of treatment in recipients of both SOT and HCT with EBV-positive PTLD.

Factors that contribute to the risk of developing PTLD include patient age, type of HCT or type of organ transplanted in SOT, type and dosage regimen of immunosuppressive drugs, and pre-transplant EBV serostatus of both donor and recipient ${ }^{[10,11]}$. The reported incidence of PTLD is between $2 \%$ and $20 \%$, with a greater number of cases in patients who receive a SOT compared to HCT recipients ${ }^{[12,13]}$. The incidence of PTLD varies by the organ(s) transplanted: intestinal and multi-organ transplants (5\%-20\%), lung and heart transplants $(2 \%-10 \%)$, and renal and liver transplants $(1 \%-5 \%)^{[14]}$. Over the past two decades, the incidence of PTLD has increased, presumably due to an increased number of organ transplants performed, use of novel immunosuppressive therapies, and improved diagnosis ${ }^{[15,16]}$. Simultaneously, a decreased risk of developing "early" EBV-positive PTLD has been reported ${ }^{[17]}$. Factors contributing to this are improved targeting of immunosuppressive medications, stringent monitoring of EBV viral load, EBV prophylaxis, and pre-emptive EBV-directed therapy ${ }^{[18]}$. Identification of modifiable risk factors should aid in delineating better strategies for prevention and treatment of EBV-positive PTLD.

Although this review will focus on EBV-associated PTLD, there are notable differences between patients with EBV-positive PTLD and those with EBV-negative PTLD. It has been demonstrated that patients with EBV-positive PTLD are typically younger, closer to transplant, and have a poorer performance status than 
those with EBV-negative PTLD ${ }^{[19]}$. Additionally, the European PTLD Network has demonstrated that while the incidence of extra-nodal disease is not significantly different between the two cohorts, those with EBVpositive PTLD are more likely to have allograft involvement and less likely to have nodal involvement ${ }^{[19]}$.

While prognostic features in patients diagnosed with PTLD after SOT and HCT have been established, these are distinct from those established for immune competent patients with non-Hodgkin lymphoma (NHL). NHL staging and prognosis depends on the number and location of involved lymph nodes, extra-nodal involvement, and presence or absence of bulky disease ${ }^{[20]}$. In contrast, the prognosis of PTLD depends on both disease-specific features (morphologic subtype, EBV positivity, and time from transplant) as well as patient-specific factors (age, EBV serostatus, co-morbidities, and ability to tolerate tapering of immunosuppression and intensive therapy $)^{[9,21]}$. Given that no uniform prognostic scoring system has been used across prior reports in patients with PTLD, it is difficult to estimate the survival chances for individual patients, but OS ranges from $25 \%$ to $92 \%$ based on risk factors ${ }^{[22]}$.

For SOT recipients, the international prognostic index (IPI) uses risk factors of age greater than 60 years, Ann Arbor stage greater than or equal to III, Eastern Cooperative Oncology Group performance status greater than or equal to 2, elevated lactate dehydrogenase (LDH), and more than one extra-nodal site of involvement ${ }^{[23]}$. It was demonstrated that baseline IPI was a highly significant independent prognostic factor for time to progression (TTP) and OS in recipients of $\mathrm{SOT}^{[8]}$. A nationwide French study constructed a prognostic score that classified patients with PTLD as being at low, moderate, high, or very-high risk for death based on five variables at diagnosis: age, serum creatinine, LDH, PTLD localization, and histology ${ }^{[22]}$. A retrospective analysis validated the French prognostic scoring system in an independent cohort of 54 recipients of kidney transplant and a total of 122 additional SOT recipients ${ }^{[24]}$. However, in this cohort, the French scoring system was not superior to the classic IPI score. Furthermore, the type of transplant is a baseline variable that has an impact on OS and disease progression, which is not included in the current scoring systems ${ }^{[23]}$. Inability to tolerate reduction in immunosuppression (RIS) and lack of response to rituximab have also been reported as poor prognostic markers ${ }^{[8]}$. Prospective validation of prognostic scoring is essential for effectively implementing risk-stratified therapies ${ }^{[24]}$.

For HCT recipients, older age, extra-nodal disease, acute graft-versus-host disease (GVHD), and inability to tolerate RIS have been associated with an inferior response to first-line rituximab therapy ${ }^{[25]}$. Factors associated with a poor response to EBV-specific CTLs (EBV-CTLs) after prior rituximab included prior receipt of multi-agent chemotherapy, extra-nodal disease, and greater than three sites of disease $\mathrm{e}^{[26,27]}$.

Treatment strategies for PTLD uniquely need to balance curative intent with the potential for injury to the transplanted organ and thus can differ from treatment of NHL in immunocompetent hosts. Furthermore, treatment strategies for PTLD after HCT differ from PTLD after SOT. Several studies demonstrate that outcomes are superior in patients on exogenous immunosuppression if that immunosuppression can be safely reduced ${ }^{[25,28-30]}$. First-line treatment in recipients of HCT is rituximab given that these patients have a high risk of significant toxicity from multi-agent chemotherapy. Though there are a few case reports showing a curative potential with multi-agent chemotherapy ${ }^{[31,32]}$, in general standard multi-agent chemotherapy is not successful and poorly tolerated in HCT recipients ${ }^{[33]}$. In contrast, the first-line treatment in PTLD emerging after SOT is RIS along with rituximab and/or multi-agent chemotherapy. Importantly, the safety of RIS varies with the organ transplanted as does the safety and tolerability of specific chemotherapy agents. In both cohorts of patients, adoptive therapy with EBV-CTLs has been explored in a series of clinical trials. 
Here we review standard chemotherapy and non-chemotherapy approaches to treatment of EBV-positive PTLD [Figure 1], highlighting some of the unique aspects of treatment for this patient population.

\section{REDUCTION IN IMMUNOSUPPRESSION}

The mainstay of first-line therapy for PTLD is RIS, which restores cellular immunity by re-establishing host $\mathrm{T}$ cell function to control lymphoproliferation ${ }^{[30,34]}$. Importantly, recipients of T-cell-depleted HCT are among those at highest risk after HCT and are not typically on exogenous immunosuppression. In addition, RIS may come at a cost of GVHD (HCT recipients) or transplant organ rejection (SOT recipients). The only prospective study evaluating RIS alone as treatment for PTLD in the SOT setting demonstrated a $6 \%$ partial response $(\mathrm{PR})$ rate with no complete responses $(\mathrm{CR})^{[35]}$. Furthermore, 38\% of patients in this trial experienced graft rejection ${ }^{[35]}$. The published response rate to RIS ranges from $0 \%$ to $73 \%$, and these responses are not typically sustained with durable responses maintained in less than $10 \%$ to $20 \%$ of cases $^{[36-42]}$. Therefore, RIS is usually implemented during the initial workup of PTLD but then combined with other treatment modalities. These other treatment modalities, such as multi-agent chemotherapy or rituximab, impair host immunity and may protect from rejection in the context of RIS. Factors predictive of poor response to RIS in adult patients are EBV-negative disease, older age, elevated LDH, multi-organ involvement at diagnosis, bone marrow and liver involvement, B symptoms (fever, night sweats, and weight loss), severe organ dysfunction, dyspnea, and hepatitis $\mathrm{C}^{[28,34]}$. In pediatric SOT recipients, identified predictors for poor response to RIS include histologic features (CD20-negative, EBV-negative, Burkitt or Hodgkin morphology), late-onset disease, and central nervous system (CNS) involvement ${ }^{[43-45]}$.

Although limited, data demonstrate that immunosuppression with sirolimus may decrease the incidence of PTLD. In pre-clinical models of PTLD, high exposure to sirolimus has a potent anti-proliferative effect ${ }^{[46]}$. The published experience of this approach for treatment of PTLD is limited to three recipients of renal transplant described in two separate case series. In one, a patient was changed from tacrolimus and mycophenolate mofetil (MMF) to sirolimus and prednisolone and then experienced rapid improvement in allograft function and regression of the tumor that was durable at one year ${ }^{[47]}$. Similarly, two recipients of renal transplant with PTLD (DLBCL) had full regression of disease after switching from MMF or azathioprine to sirolimus ${ }^{[48]}$. Prospective clinical analysis is warranted to explore this further.

\section{CD20 MONOCLONAL ANTIBODIES}

Rituximab, a first-generation chimeric monoclonal antibody targeting the B-cell surface protein $\mathrm{CD} 20$, has improved outcomes in many CD20-positive NHLs, such as DLBCL and follicular lymphoma. Rituximab is a standard component in the treatment of these CD20-positive lymphomas based upon a demonstrated survival benefit ${ }^{[4]}$. For recipients of HCT, American and European guidelines support pre-emptive treatment of EBV viremia with rituximab before the diagnosis of PTLD is established, while the role of preemptive treatment is less well established in $\mathrm{SOT}^{[50,51]}$. Rituximab is effective in EBV-positive PTLD because it directly targets the CD20-positive tumor. It may also improve disease control by residual EBV-CTLs by improving the effector to target cell ratio (E:T) of EBV-CTLs to EBV-infected B cells ${ }^{[33]}$. The major toxicities of rituximab include infusion reactions (e.g., fevers, rigors, and hypotension), cytopenias, infections related to immunosuppression, impaired humoral immune recovery, and prolonged hypogammaglobulinemia ${ }^{[49]}$.

A landmark retrospective review of PTLD emerging after HCT was performed by the European Group for Blood and Marrow Transplantation (EBMT) ${ }^{[26]}$. PTLD developed in 144 (3.22\%) of 4446 transplants performed between 1999 and 2011, and survival was $69.4 \%{ }^{[26]}$. Multivariable analysis revealed that a poor response to rituximab was associated with the following prognostic factors: age greater than or equal to 30 years, extra-nodal involvement, acute GVHD, and a failure to reduce immunosuppression at the time of 


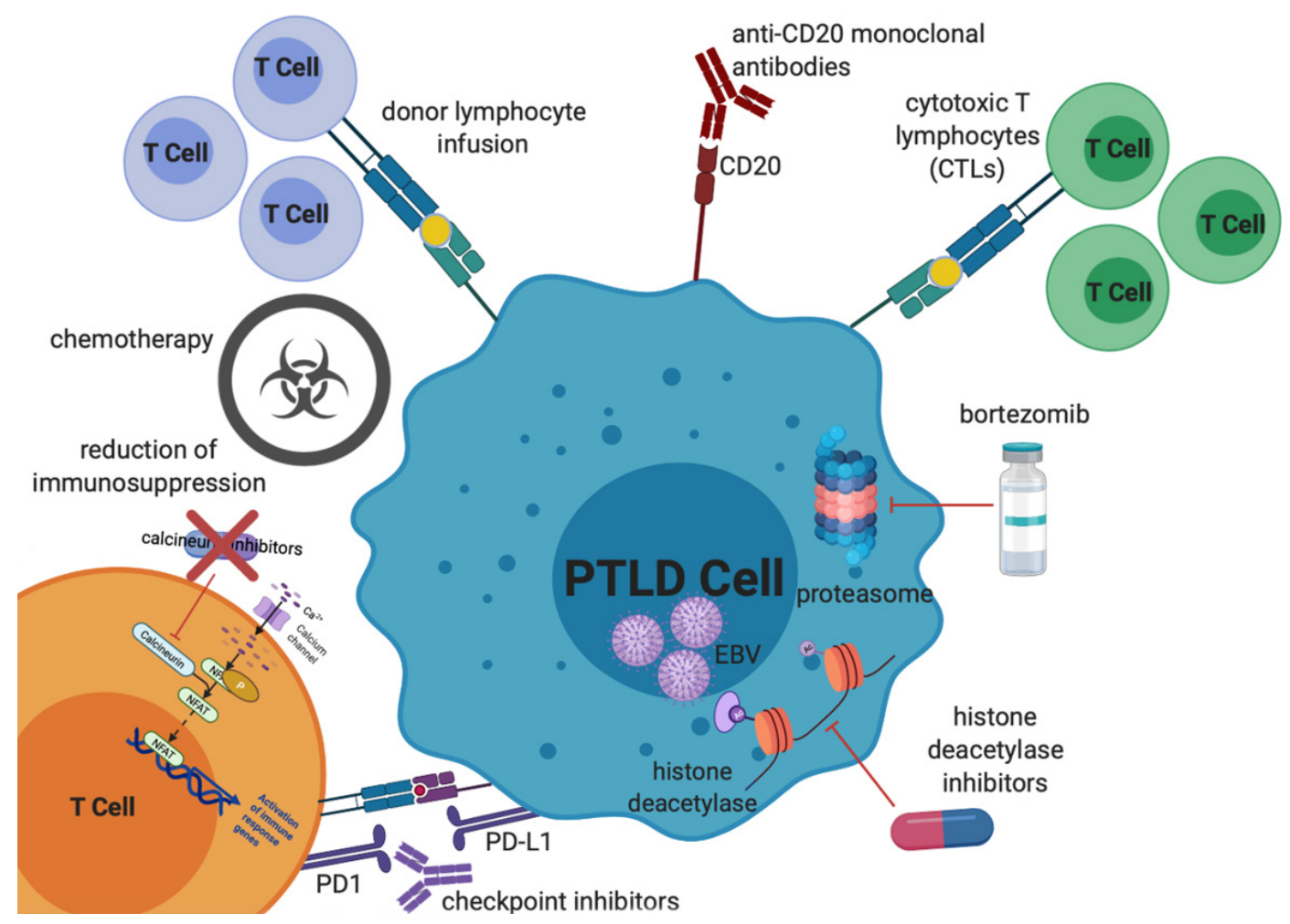

Figure 1. Mechanisms of treatment of EBV PTLD. Treatment options, which will all be discussed in further detail in this review, include reduction of immunosuppression, chemotherapy (including classical multi-agent lymphoma-based regimens as well as single agent anti-metabolite therapy), donor lymphocyte infusions, anti-CD20 monoclonal antibodies, cytotoxic T lymphocytes, proteasome inhibitors, histone deacetylase inhibitors, and checkpoint inhibitors. EBV: Epstein-Barr virus; PTLD: post-transplant lymphoproliferative disorder.

diagnosis of PTLD ${ }^{[26]}$. PTLD mortality significantly increased with an increasing number of factors: zero to one, two, or three factors being associated with mortality of $7 \%, 37 \%$, and $72 \%$, respectively ${ }^{[26]}$. Both RIS at diagnosis and decreasing EBV viremia with initiation of therapy were predictive of an improved chance of survival ${ }^{[26]}$.

Single-agent rituximab achieves a CR in approximately $20 \%$ of patients with PTLD following either SOT or

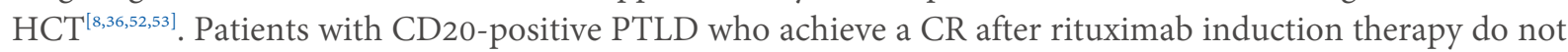
require chemotherapy ${ }^{[8]}$. However, they do remain at risk of recurrence. Single-agent rituximab was employed in a prospective multicenter phase II trial involving 43 evaluable patients with previously untreated CD20-positive PTLD that did not respond to tapering of immunosuppression ${ }^{[54]}$. The overall response rate (ORR) was $44 \%$, while OS was $86 \%$ and $67 \%$ at 80 days and 1 year, respectively ${ }^{[54]}$. In another study, 60 SOT recipients with PTLD treated with single-agent rituximab had an ORR of $59 \%(42 \% \mathrm{CR})^{[55]}$. Half experienced disease progression within 6 months of completion of rituximab therapy ${ }^{[55]}$. Median OS was 35 months with 1 - and 2-year OS rates of $73 \%$ and $52 \%$, respectively ${ }^{[55]}$. In an international phase II trial, four additional courses of rituximab were administered to 37 of the 148 patients (25\%) who achieved CR after four weekly doses of rituximab induction therapy for CD20-positive PTLD ${ }^{[8]}$. At 3 years, the estimated progression-free survival (PFS) and OS were $89 \%$ and $91 \%$, respectively, among those who achieved CR after rituximab induction therapy ${ }^{[8]}$. In this trial, there was no significant difference in ORR, TTP, or OS between those with EBV-positive and EBV-negative PTLD ${ }^{[8]}$. Another prospective, multicenter, phase II trial in which PTLD patients who did not achieve a CR after RIS and four weekly infusions of rituximab 
then received a second course of four infusions revealed that extended treatment with rituximab can obtain a high rate of CR in patients with PTLD after SOT without increasing toxicity ${ }^{[56]}$.

Second and third generation CD20 monoclonal antibodies that decrease the murine components of rituximab include the fully human anti-CD20, ofatumumab (OFA), and the humanized anti-CD20, obinutuzumab (OBZ). Similar to rituximab, OFA is a type I anti-CD20 antibody and mediates efficacy by both complement- and Fc-mediated cytotoxicity ${ }^{[57]}$. OBZ, however, is a type II antibody and has limited complement-mediated cytotoxicity ${ }^{[58]}$. OFA is associated with a high frequency of infusion reactions, which are potentially fatal, and therefore requires steroid premedication ${ }^{[59]}$. OFA is also associated with more significant cytopenias. However, OFA is appropriate for patients with human anti-mouse antibodies (HAMA) or a history of serum sickness to rituximab ${ }^{[00]}$.

\section{CHEMOTHERAPY}

The role of multi-agent chemotherapy for EBV-positive PTLD is very different in HCT vs. SOT patients and will be addressed separately.

In the treatment of EBV-positive PTLD emerging after HCT, multi-agent chemotherapy use has been limited to patients with a demonstrated first response to rituximab ${ }^{[33]}$. A retrospective study showed the limited efficacy of chemotherapy in patients who failed rituximab with no patient attaining $\mathrm{CR}^{[31]}$.

In SOT recipients, however, multi-agent chemotherapy has an established role for patients with CD20positive PTLD ${ }^{[6]}$. Classically used regimens are rituximab, cyclophosphamide, doxorubicin, vincristine, and prednisone (R-CHOP) and dose-adjusted etoposide, prednisone, vincristine, cyclophosphamide, doxorubicin, and rituximab (EPOCH-R). There have been no randomized trials comparing different chemotherapy regimens in PTLD, and so physician experience and toxicity profile typically guide chemotherapy regimen selection. Furthermore, there are no trials that directly compare upfront chemoimmunotherapy to rituximab alone in CD20-positive PTLD.

Sequential treatment of CD20-positive PTLD (clinicaltrials.gov NCT01458548) established risk-stratified sequential treatment with four doses of rituximab with subsequent $\mathrm{CHOP}$ chemotherapy stratified based on response to rituximab. This is now becoming standard in the management of PTLD emerging after SOT and allows response to rituximab to be used as a prognostic factor for $\mathrm{OS}^{[8]}$. This group then hypothesized that rituximab consolidation might be sufficient treatment for patients with a CR after rituximab induction ${ }^{[8]}$. In a prospective, international, multicenter phase II trial, 152 treatment-naive adult SOT recipients with $\mathrm{CD} 20$-positive PTLD unresponsive to RIS were treated with four weekly doses of rituximab $^{[8]}$. After restaging, complete responders received four courses of rituximab consolidation every 21 days; those not achieving a CR to induction rituximab received four courses of R-CHOP chemotherapy also in 21-day cycles ${ }^{[8]}$. One hundred and eleven of 126 patients had a complete or partial response (88\%; 95\%CI: $81 \%-93 \%)$, of whom 88 had a CR $(70 \% \text {; } 95 \% \text { CI: } 61 \%-77 \%)^{[8]}$. Median OS was 6.6 years (95\%CI: 5.5-7.6 years ${ }^{[8]}$. The frequency of grade three or four infections and of treatment-related mortality was $34 \%$ (95\%CI: $27 \%-42 \%$ ) and $8 \%$ (95\%CI: 5\%-14\%), respectively ${ }^{[8]}$. Response to rituximab induction remained a prognostic factor for OS despite treatment stratification ${ }^{[8]}$. This study concluded that in patients with PTLD, response to initial rituximab treatment can be used to stratify subsequent therapy into rituximab or RCHOP consolidation and that this approach is feasible, safe, and effective. 
An approach established in pediatrics in a phase II multicenter trial (clinicaltrials.gov NCT00066469) demonstrated safety and efficacy in combining low-dose cyclophosphamide and either prednisone or methylprednisolone with rituximab in pediatric and young adult patients who have CD20-positive EBVpositive PTLD following SOT ${ }^{[62]}$. Toxicity was similar for cycles of therapy with $v s$. without rituximab ${ }^{[62]}$. The CR rate was 69\% (95\%CI: 57\%-84\%) $)^{[62]}$. In addition, response appeared to improve after the completion of therapy: eight of 12 patients with radiographic evidence of persistent disease at the end of therapy achieved a CR by 28 weeks without further PTLD-directed therapy ${ }^{[62]}$. There were 10 deaths: three due to infections while receiving therapy and seven from PTLD ${ }^{[62]}$. The 2-year EFS was $71 \%(95 \% \mathrm{CI}$ : 57\%-82\%) and OS was $83 \%$ (95\%CI: 69\%-91\%) $)^{[62]}$. Based on these results, rituximab combined with low-dose chemotherapy has been adopted as first-line therapy by many clinicians for PTLD in pediatric recipients of SOT.

\section{OTHER AGENTS}

Although currently not considered standard of care, other treatments such as bortezomib, bendamustine, and immune checkpoint inhibitors have been explored in the treatment of PTLD. Bortezomib, a proteasome inhibitor, is Food and Drug Administration (FDA)-approved to treat multiple myeloma and mantle cell lymphoma. It shows significant activity in lymphomas associated with EBV. A recent study (clinicaltrials.gov NCT01058239) in adult patients examined the effect of the addition of bortezomib to rituximab in the treatment of PTLD after SOT or HCT. A total of 7 patients were enrolled. ORR at 4 months was $42.9 \%$, CR at 4 months was $42.9 \%$, and PFS at 6 months was $43 \%$. Adverse events were reported in all treated patients, for whom $28.6 \%$ were serious adverse events. Final results of this study are currently pending publication. Alternatively, bendamustine plus rituximab has demonstrated efficacy and a favorable

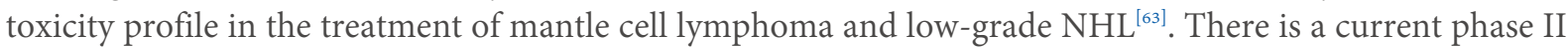
trial evaluating bendamustine combined with rituximab in patients with previously untreated PTLD (clinicaltrials.gov NCT02753062).

Microsatellite instability (MSI), due to mutations or deletions of genes involved in DNA mismatch repair, results in an accumulation of mutations. MSI has not been found in lymphomas developing in immunecompetent individuals but has been reported in PTLD, unrelated to EBV status. In a series of 111 PTLD patient samples, $8.1 \%$ had microsatellite instability ${ }^{[6]}$. Programmed cell death protein 1 (PD-1) blockade has shown clinical benefit in MSI-high tumors after previous therapy ${ }^{[65]}$. Several series ${ }^{[6-68]}$ have demonstrated a potential role for the PD-1/PD-L1 and PD-L2 pathway, including a nationwide study of 81 cases with $67 \%$ of PTLD diagnosed after SOT expressing PD-1 (on tumor-associated macrophages) and PD-L1/PD-L2 (on malignant cells ${ }^{[6 \sigma]}$. Gene expression profiling and analysis of copy number alteration (CNA) identified a prevalent CNA of the terminal region of chromosome 9 with expression data suggesting that PD-L2 is the target of this alteration ${ }^{[67]}$. However, there is limited experience in the treatment of PTLD with checkpoint blockade. A case report described control of EBV-positive PTLD in CNS with PD1 checkpoint blockade ${ }^{[6]}$. However, in preclinical mouse models PD-1 blockade aggravated the progression of EBV-positive PTLD ${ }^{[70]}$. Furthermore, there is a high potential risk of T-cell mediated allograft rejection and GVHD with the use of immune checkpoint inhibition in recipients of SOT and HCT.

Other novel agents currently in clinical trials for EBV-positive PTLD include nivolumab with EBV-CTLs (clinicaltrials.gov NCT02973113), brentuximab vedotin with rituximab (clinicaltrials.gov NCT01805037), everolimus with lenalidomide (clinicaltrials.gov NCT01075321), and everolimus with panobinostat (clinicaltrials.gov NCT00918333). Results of these studies will help elucidate the role of these novel therapies in EBV-positive PTLD. 


\section{EBV-TARGETED THERAPIES}

Typically, EBV-positive PTLD has a latency III EBV gene expression pattern ${ }^{[71,72]}$. In these tumors, EBVinduced B-cell transformation is sufficient to induce full malignant potential without secondary genetic or epigenetic changes ${ }^{[7]}$. These tumors are therefore different in pathogenesis from other EBV-positive malignancies where viral infection is the first event and then subsequent events such as c-myc translocations are required for malignant transformation ${ }^{[68,7]}$. For this reason, viral directed therapies are an appealing approach for PTLD.

\section{HDAC inhibitors combined with antivirals}

Several antiviral compounds have been tested in the clinic against EBV-associated lymphomas, and in general, reproducible activity has been difficult to document ${ }^{[73]}$. Antivirals such as ganciclovir require lyticphase proteins, including viral kinases (TK), to convert these drugs to active antivirals ${ }^{[73]}$. Thus, these drugs are not very effective at eliminating EBV in chronically infected hosts where the virus persists in a latent state. Induction of EBV TK within EBV-positive lymphomas is predicted to result in sensitization of these tumor cells to antiviral agents such as ganciclovir ${ }^{[74]}$. This approach is expected to have high tumor specificity based on targeting of EBV-containing cells.

The nucleoside analogs acyclovir and ganciclovir have activity against the EBV lytic phase TK, providing the rationale for attempts to induce expression of EBV lytic phase genes, including viral TK, as a way to sensitize EBV-infected targets to these agents ${ }^{[75,76]}$. As proof of concept, a cell line derived from a lung transplant recipient's EBV-associated lymphoma was exposed to arginine butyrate, a histone deacetylase (HDAC) inhibitor, resulting in induction of EBV TK transcription, and culture in the presence of ganciclovir resulted in cell cycle arrest and cell death ${ }^{[7]}$.

This approach was explored in a Phase I/II study of arginine butyrate combined with ganciclovir. Fifteen patients with chemotherapy and/or radiation refractory EBV-positive PTLD were treated ${ }^{[78]}$. Antitumor activity was observed in 10 patients, with four CRs and six PRs. The most common toxicities were nausea and headache, the most common severe adverse events were related to the CNS, and rapid tumor lysis occurred in 3 patients.

Several other HDAC inhibitors can induce expression of EBV lytic phase genes in vitro, leading to the sensitization to nucleoside antivirals ${ }^{[74,77]}$. An actively recruiting Phase $1 \mathrm{~b} / \mathrm{II}$ study (clinicaltrials.gov NCT03397706) is designed to define a recommended Phase II dose of VRx-3996, an HDAC inhibitor, in combination with valganciclovir (Phase $1 \mathrm{~b}$ ) and to evaluate the efficacy of this combination in relapsed/refractory EBV-positive lymphomas (Phase II). There is also an active phase II trial of panobinostat, an HDAC inhibitor, monotherapy in patients with refractory lymphomas (clinicaltrials.gov NCT01261247).

\section{EBV cytotoxic lymphocytes}

Adoptive cell therapy with EBV-CTLs or donor leukocyte infusion (DLI) transfers naturally occurring EBVspecific cytotoxic T cells that can kill EBV-transformed B cells into recipients with EBV-associated PTLD. This infusion of pathogen-specific $\mathrm{T}$ cells has been explored as a method to reconstitute viral-specific immune responses in the post-transplant period. Adoptive cell therapy relies on the fact that upon encountering a specific viral antigen presented by a specific and shared HLA allele, pathogen-specific T cells undergo in vivo expansion and mediate control of the infection. In contrast to chemotherapeutic approaches, adoptive cell therapy offers the potential to establish viral specific T cell memory while avoiding immune-ablation and organ toxicity ${ }^{[79]}$. 
The initial demonstration that EBV-specific immunity can be transferred effectively was over 25 years ago in five recipients of T-cell-depleted allogeneic HCT who developed EBV-associated PTLD ${ }^{[80]}$. Patients received infusions of unirradiated DLI from their EBV-seropositive HCT donor, and all 5 patients had complete pathological or clinical responses ${ }^{[80]}$. This illustrated that unirradiated DLI was an effective source of EBV-specific T cell immunity for treatment for EBV-associated PTLD that arose after allogeneic HCT. However, it was associated with a significant risk of GVHD caused by the simultaneous transfer of alloreactive T cells.

Adoptive immunotherapy with EBV-CTLs generated from primary HCT donors is effective in the treatment of EBV disease complicating allogeneic HCT [Table 1]. EBV-specific CTLs have been effective in more than $80 \%$ of patients treated for overt $\mathrm{PTLD}^{[8]]}$, a finding confirmed by other investigators in the treatment of transplant recipients with rituximab-resistant $\mathrm{PTLD}^{[82-85]}$. In SOT recipients, this approach is more challenging as the EBV-positive PTLD is typically of host origin and the organ donor is typically not HLA compatible and therefore not an appropriate source of EBV-CTLs. In addition, SOT recipients require long-term immunosuppression. Despite these challenges, several studies have demonstrated that autologous EBV-CTLs can be generated from recipients of SOT and when infused for treatment of EBV-positive PTLD, they can eradicate disease and restore EBV-specific immunity ${ }^{[8-88]}$.

The generation and use of donor-derived EBV-CTLs has thus far been explored on investigational protocols, but broader accessibility has been challenging. In addition to the specialized facilities required to generate cellular therapy products, other issues have limited accessibility of adoptive $\mathrm{T}$ cell therapy. These limitations have included the time (2-3 months) required to generate EBV-CTLs for adoptive therapy using the original methods. Given the rapid progression of disease in patients with EBV PTLD refractory to rituximab, donor-specific products would need to be generated before the onset of disease. Given the relatively low incidence of rituximab-refractory EBV-positive PTLD, this is not feasible.

One early approach to address these limitations was the use of non-toxic bridge therapy with agents such as hydroxyurea ${ }^{[89]}$. More recently, there have been two additional approaches to circumvent these limitations: one is development of techniques allowing the more rapid generation of EBV-CTLs and the second is the generation of banks of third-party EBV-CTLs available for immediate off-the-shelf use. A number of centers, and now commercial enterprises, have generated such banks of allogeneic EBV-CTLs with a published experience of 124 patients treated [Table 2].

The earliest demonstration of the potential safety of third-party EBV-CTLs was in 8 patients with EBV PTLD arising after SOT for whom autologous EBV-CTLs were not available ${ }^{[0]}$. This approach was expanded to a phase II clinical trial that treated 33 patients and resulted in a $64 \%$ response rate. In this study, recipients received EBV-CTL lines that were best matched for HLA defined at low resolution. Responses were better in those patients receiving EBV-CTLs that were matched at a higher number of HLA alleles and that had a higher fraction of $\mathrm{CD} 4$-positive $\mathrm{T}$ cells ${ }^{[91]}$. Another 5 patients treated with third-party EBV-CTLs resulted in four responders ${ }^{[92,93]}$, and ten pediatric SOT recipients produced an $80 \%$ overall remission rate ${ }^{[94]}$. A third-party, allogeneic, off-the-shelf bank of 330 GMP-grade EBV-CTL lines from specifically consented healthy EBV-seropositive HCT donors was used to treat 46 recipients of HCT ( $n=$ 33) or SOT ( $n=13$ ) with established EBV-positive PTLD, whose disease had failed to respond to or relapsed after rituximab therapy ${ }^{[27]}$. CR or sustained PR was achieved in $68 \%$ of HCT recipients and $54 \%$ of SOT recipients ${ }^{[27]}$. For patients who achieved CR/PR or stable disease after cycle one, one-year OS was $88.9 \%{ }^{[27]}$ and $81.8 \%$, respectively ${ }^{[27]}$. In addition, three of five recipients with progression of disease after a first cycle who received EBV-CTLs from a different donor achieved CR or durable PR (60\%) and survived longer than 
Table 1. Experience using adoptive T-cell therapy for PTLD: donor-derived EBV CTLs

\begin{tabular}{|c|c|c|c|c|c|}
\hline Study & Method of selection & Treatment setting & $N$ & Response (CR + PR) & Acute GVHD \\
\hline $\begin{array}{l}\text { Rooney et al. }{ }^{[116,117]} \\
\text { Heslop et al. }{ }^{[18]}\end{array}$ & EBV-LCL sensitized & PTLD & 13 & $11 / 13$ & $8 \%$ \\
\hline Lucas et al. ${ }^{[119]}$ & EBV-LCL sensitized & PTLD & 1 & $1 / 1$ & $100 \%$ \\
\hline Imashuku et al. ${ }^{[120]}$ & EBV-LCL sensitized & PTLD & 1 & $0 / 1$ & $0 \%$ \\
\hline Gottschalk et al. ${ }^{[102]}$ & EBV-LCL sensitized & PTLD & 1 & $0 / 1$ & Not documented \\
\hline Comoli et al..$^{[121]}$ & EBV-LCL sensitized & PTLD & 5 & $5 / 5$ & $0 \%$ \\
\hline Moosman et al. ${ }^{[122]}$ & Peptide stimulation IFN $\gamma$ capture & PTLD & 6 & $3 / 6$ & $0 \%$ \\
\hline Doubrovina et al. ${ }^{[99]}$ & EBV-LCL sensitized & PTLD & 19 & $13 / 19$ & $0 \%$ \\
\hline Icheva et al. ${ }^{[123]}$ & $\begin{array}{l}\text { EBNA-1 peptide stimulation } \\
\text { IFN } \gamma \text { capture }\end{array}$ & PTLD & 8 & $6 / 8$ & $13 \%$ \\
\hline Gerdemann et al..$^{[124]}$ & DC nucleofection viral plasmids & PTLD & 1 & $1 / 1$ & $100 \%$ \\
\hline Papadopoulou et al. ${ }^{[96]}$ & Peptide-stimulated & PTLD & 1 & $1 / 1$ & $0 \%$ \\
\hline
\end{tabular}

PTLD: Post-transplant lymphoproliferative disorder; EBV CTLs: Epstein-Barr virus cytotoxic T cell lines; CR: complete responses; PR: partial response; GVHD: graft-versus-host disease.

Table 2. Experience using adoptive T-cell therapy for PTLD: third party EBV-CTLs

\begin{tabular}{|c|c|c|c|c|c|c|}
\hline Study & Method of selection & Treatment setting & Prior therapy & $\mathbf{N}$ & HLA & Response (CR + PR) \\
\hline $\begin{array}{l}\text { Alabama } \\
\text { Sun et al. }{ }^{[93]} \\
\text { Lucas et al. }{ }^{[125]}\end{array}$ & $\begin{array}{l}\text { EBV-BLCL sensitized } \\
\text { EBV-CTL }\end{array}$ & PTLD SOT & $\begin{array}{l}\text { RT } \\
\text { Rituximab/C }\end{array}$ & $\begin{array}{l}1 \\
1\end{array}$ & $\begin{array}{l}4 / 6 \\
6 / 6\end{array}$ & $\begin{array}{l}1 / 1(100 \%) \\
1 / 1(100 \%)\end{array}$ \\
\hline $\begin{array}{l}\text { Edinburgh } \\
\text { Haque et al. }{ }^{[91]}\end{array}$ & EBV-LCL sensitized EBV-CTL & $\begin{array}{l}\text { PTLD HCT } \\
\text { SOT }\end{array}$ & $\begin{array}{l}\text { RIS } \\
\text { Rituximab/C }\end{array}$ & $\begin{array}{l}2 \\
31\end{array}$ & $\begin{array}{l}2-5 / 6 \\
2-5 / 6\end{array}$ & $\begin{array}{l}2 / 2(100 \%) \\
19 / 31(61 \%)\end{array}$ \\
\hline $\begin{array}{l}\text { Australia } \\
\text { Gandhi et al. }{ }^{[92]}\end{array}$ & EBV-LCL sensitized EBV-CTL & PTLD SOT & $\begin{array}{l}\text { RIS } \\
\text { Rituximab/C }\end{array}$ & 3 & $\geq 3 / 6$ & $2 / 3(66 \%)$ \\
\hline $\begin{array}{l}\text { Baylor } \\
\text { Leen et al. }^{[126]}\end{array}$ & Transduced multivirus & PTLD HCT & Rituximab & 9 & $\geq 1$ & $6 / 9(67 \%)$ \\
\hline $\begin{array}{l}\text { Inserm } \\
\text { Gallot et al. }{ }^{[127]}\end{array}$ & $\begin{array}{l}\text { EBV-LCL sensitized } \\
\text { EBV-CTL }\end{array}$ & $\begin{array}{l}\text { PTLD HCT } \\
\text { SOT }\end{array}$ & $\begin{array}{l}\text { Rituximab/C } \\
\text { Rituximab/C }\end{array}$ & $\begin{array}{l}6 \\
3\end{array}$ & $\begin{array}{l}\geq 2 \\
\geq 2\end{array}$ & $\begin{array}{l}3 / 6(50 \%) \\
1 / 3(30 \%)\end{array}$ \\
\hline $\begin{array}{l}\text { UK } \\
\text { Chiou et al. }{ }^{[94]}\end{array}$ & $\begin{array}{l}\text { EBV-LCL Stimulated } \\
\text { EBV-CTL }\end{array}$ & PTLD SOT & Rituximab/RIS & 10 & Not specified & $8 / 10(80 \%)$ \\
\hline $\begin{array}{l}\text { Aberdeen } \\
\text { Vickers et al. }{ }^{[128]}\end{array}$ & $\begin{array}{l}\text { EBV-LCL Stimulated } \\
\text { EBV-CTL }\end{array}$ & $\begin{array}{l}\text { PTLD HCT } \\
\text { SOT }\end{array}$ & $\begin{array}{l}\text { N/A } \\
\text { N/A }\end{array}$ & $\begin{array}{l}6 \\
4\end{array}$ & $\begin{array}{l}\geq 3 \\
\geq 3\end{array}$ & $\begin{array}{l}4 / 6(67 \%) \\
4 / 4(80 \%)\end{array}$ \\
\hline $\begin{array}{l}\text { Baylor } \\
\text { Tzannou et al. }^{[95]}\end{array}$ & Peptide stimulated & PTLD HCT & None & 1 & $3 / 8$ & $1 / 1(100 \%)$ \\
\hline $\begin{array}{l}\text { MSK } \\
\text { Prockop et al. }{ }^{[27]}\end{array}$ & $\begin{array}{l}\text { EBV-LCL sensitized } \\
\text { T-cell line }\end{array}$ & $\begin{array}{l}\text { PTLD HCT } \\
\text { SOT }\end{array}$ & $\begin{array}{l}\text { Rituximab/C } \\
\text { Rituximab/C }\end{array}$ & $\begin{array}{l}33 \\
13\end{array}$ & $\begin{array}{l}2-5 / 10 \\
2-4 / 10\end{array}$ & $\begin{array}{l}22 / 33(68 \%) \\
7 / 13(54 \%)\end{array}$ \\
\hline $\begin{array}{l}\text { Spain } \\
\text { Alonso et al. }{ }^{[129]}\end{array}$ & Not specified & PTLD HCT & Not documented & 1 & Not documented & $0 / 1(0 \%)$ \\
\hline
\end{tabular}

PTLD: Post-transplant lymphoproliferative disorder; EBV CTLs: Epstein-Barr virus cytotoxic T cell lines; CR: complete responses; PR: partial response.

one year. Maximal responses were achieved after a median of two cycles ${ }^{[2]}$. These results suggest that thirdparty EBV-CTLs should be further explored as therapy for rituximab-refractory EBV-positive PTLD emerging after either HCT or SOT.

Limited studies have demonstrated the durability of clinical responses to EBV-CTLs. A recent phase II clinical trial showed that both CR and PR to EBV-CTLs in SOT and HCT groups have been durable (6-115 months $)^{[27]}$. In contrast, PRs with chemotherapy treatment typically are not durable. Although PRs to CTLs have been durable, there is no clinically validated definition for this assessment. For example, some institutions define a PR as a decrease in viral load by quantitative PCR of at least 50\% from baseline or a 50\% 
improvement in clinical signs and symptoms ${ }^{[95,96]}$. In contrast, other centers define a PR as a two-log decrease in viral load and resolution of symptoms ${ }^{[27]}$. There is a clear need for uniformity in disease assessment among clinicians.

The requirement for persistence of EBV-CTLs to maintain durable responses is also not defined. As long as $18^{[97]}$ and $24^{[27]}$ months after infusion of donor- or third-party-derived EBV-CTLs, it was possible to demonstrate the presence of CTL precursors responsive to either in vivo or ex vivo re-challenge. However, specialized techniques are required to demonstrate the origin of these precursors. Long-term follow-up of a cohort of patients treated with gene-marked donor-derived EBV-CTLs showed persistence of the EBVCTLs even nine years after infusion ${ }^{[98]}$. In addition, persistence of viral-specific immunity may not depend on persistence of the infused populations. The development of epitope spreading beyond the initially targeted EBV antigens has been demonstrated with autologous products and may be critical for promoting and sustaining the antitumor response. This phenomenon implies a beneficial interaction between the infused populations and the tumor microenvironment and suggests that adoptive therapy with EBV-specific $\mathrm{T}$ cell therapy may potentiate reconstitution of EBV-specific immunity ${ }^{[98]}$. Therefore, persistence is not necessarily required for durability of response.

The primary safety concerns surrounding adoptive immunotherapy is GVHD in the HCT setting and allograft rejection in the SOT setting. As the frequency of circulating alloreactive $\mathrm{T}$ cells is similar, if not higher, than that of EBV-specific T cells in normal seropositive individuals, infusion of bulk donor lymphocytes carries a significant risk of GVHD or organ rejection. An evaluation of HCT donor-derived HLA-compatible DLI and HCT donor-derived HLA-compatible or disparate EBV-CTLs in 49 HCT recipients with biopsy-proven EBV-positive PTLD found reversible acute GVHD occurred in recipients of DLIs (17\%) but not EBV-CTLs ${ }^{[99]}$. Overall, across studies of both donor-derived and third-party-derived EBV-CTLs, the incidence of GVHD has been limited ${ }^{[86,88]}$.

As a result of the efficacy and safety demonstrated to date, EBV-CTLs are considered an attractive therapeutic option and are included in the National Comprehensive Cancer Center (NCCN) guidelines for treatment of EBV-positive PTLD. While historically this approach was not broadly available, there are currently multicenter trials underway [Table 3] evaluating EBV-CTLs in rituximab-refractory EBV-positive PTLD, including at least one registrational trial (clinicaltrails.gov NCT03394365). While these trials are currently accruing without results available, the potential for an FDA-approved product is on the horizon.

Resistance to CTL therapy has been demonstrated to be contingent on multiple factors that are both recipient- and tumor-related and are important to define in order to improve upon experience to date. In the HLA disparate setting, it is important to ensure that partially HLA-matched EBV-CTLs are restricted by an HLA allele shared by the patient's disease. Prior studies, both in mice bearing multiple EBV-BLCL xenografts ${ }^{[100]}$ and in patients receiving transplant donor-derived EBV-CTLs ${ }^{[101]}$, have shown that such T cells selectively accumulate in and only induce remissions of tumors co-expressing EBV and the HLA allele by which the EBV-CTLs are restricted. Since third-party EBV-CTLs are rarely fully HLA-matched, they may be restricted by HLA alleles not shared by the patient's disease. Thus, selection on the basis of HLA restriction should supersede selection based on the number of shared HLA alleles. Additionally, mutations in tumor-specific antigens may lead to tumor escape as demonstrated by differential cytotoxicity against targets transformed with the endogenous strain of EBV compared to the B95.8 $\operatorname{strain}^{[99]}$. This was demonstrated in a patient where the major activity of the donor CTLs was directed against two HLA-A11presented epitopes of the viral EBNA-3B antigen. Sequence analysis of the tumor revealed a deletion that removed both epitopes making it so that the tumor could not be recognized by the adoptively transferred 
Table 3. Currently recruiting EBV CTL trials for PTLD

\begin{tabular}{lll}
\hline Study & Intervention & Disease status \\
\hline $\begin{array}{l}\text { NCT03131934 } \\
\text { Phase I }\end{array}$ & $\begin{array}{l}\text { Tacrolimus-resistant autologous EBV } \\
\text { CTLs }\end{array}$ & Newly diagnosed or rituximab refractory in SOT patients \\
$\begin{array}{l}\text { NCT02779439 } \\
\text { Phase I }\end{array}$ & $\begin{array}{l}\text { HLA-matched third-party donor- } \\
\text { derived specific CTLs }\end{array}$ & Viral infection following allogeneic HCT or SOT \\
$\begin{array}{l}\text { NCT02900976 } \\
\text { Phase II }\end{array}$ & Rituximab + LMP-specific T cells & Newly diagnosed, relapsed, or refractory in SOT patients \\
$\begin{array}{l}\text { NCT03394365 } \\
\text { Phase III }\end{array}$ & Tabelecleucel & $\begin{array}{l}\text { (1) SOT after failure of rituximab and rituximab plus chemotherapy; or (2) } \\
\text { NCT02822495 }\end{array}$ \\
$\begin{array}{l}\text { Expanded access } \\
\text { allogeneic HCT after failure of rituximab }\end{array}$
\end{tabular}

EBV CTLs: Epstein-Barr virus cytotoxic T cell lines; PTLD: post-transplant lymphoproliferative disorder; HCT: hematopoietic cell transplantation; LMP: latent membrane protein.

EBV-CTLs ${ }^{[102]}$. Secondary treatment with EBV-CTLs restricted by a different HLA allele presenting a different vial epitope (called "switch therapy") can overcome this event and induce remissions if initial EBV-CTLs are ineffective ${ }^{[27]}$. However, in addition to mutations of endogenous viral genes, the latency program expression by EBV-infected tumor cells is critical to the immunogenicity of EBV tumors and their recognition by adoptively transferred EBV-CTLs.

Despite advances in adoptive T cell therapy for EBV-positive lymphomas that express the full EBV latency III program, most non-PTLD EBV-positive lymphomas express the latency I and II programs, in which there are a more limited array of EBV encoded proteins presented - Epstein-Barr nuclear antigen (EBNA1) and latent membrane proteins (LMP 1 and 2), respectively. These programs are poorly immunogenic, enabling tumors to evade adoptively transferred $\mathrm{T}$ cells that more typically recognize the EBNA2 and 3 epitopes. In Burkitt lymphoma, progress is being made by identifying potent inducers of immunogenic EBV antigens such as the nucleic acid synthesis inhibitor, decitabine. Decitabine induces expression of the more immunogenic latent viral antigens expressed in EBV type II and III latency tumors, such as PTLD. Expression of these viral antigens in EBV I latency tumors, like Burkitt lymphoma, could improve the activity of virus-directed immunotherapies against these tumors ${ }^{[103]}$. In Hodgkin lymphoma and extranodal NK/T-cell lymphoma, which typically express the latency II program, treatment with autologous T cells directed to the LMP1 and/or LMP2 antigens has been reported as a safe and effective approach to induce durable complete responses without significant toxicity ${ }^{[9,104,105]}$.

One limitation to the durable efficacy of adoptively transferred EBV-CTLs in recipients of SOT may be the need for long-term immunosuppression to prevent allograft rejection in these patients. While durable responses have been seen in this patient population, strategies to protect adoptively transferred $\mathrm{T}$ cells from the immunosuppressive environment could improve on these results. One strategy is to genetically engineer EBV-CTLs to be resistant to calcineurin inhibitors (cyclosporin A and tacrolimus), the most critical drugs used to prevent rejection after SOT and GVHD after HCT. Calcineurin inhibitors function by binding to cyclophilin (CyPA) and FK binding protein-12 (FKBP-12), respectively ${ }^{[106]}$. These complexes inhibit the calcium-sensitive phosphatase calcineurin from binding to the transcription factor nuclear factor of activated T cells (NFAT) and prevent T cells activation ${ }^{[106]}$. To neutralize the immunosuppressive effects of these drugs, calcineurin mutants disrupt binding of tacrolimus-FKBP-12 and/or cyclosporin-CyPA without affecting the active site responsible for NFAT dephosphorylation ${ }^{[107]}$. EBV-CTLs expressing such mutants maintain their proliferative capacity and interferon $\gamma$ secretion in response to stimulation with $\mathrm{EBV}^{[107]}$. An alternative way to protect adoptively transferred EBV-CTLs is to make them resistant to corticosteroids. Corticosteroid-resistant CTLs have also been developed but not yet applied to the setting of PTLD. Zinc 
finger nucleases that disrupt the glucocorticoid receptor gene in glioblastoma-specific CTLs prevent corticosteroid suppression of anti-tumor activity and permit the clinical use of an allogeneic cell product ${ }^{[108]}$.

\section{EBV cytotoxic lymphocytes combined with other therapies}

There have been several attempts to combine EBV-CTLs with other agents in a multidisciplinary approach. For example, successful management of refractory EBV-associated PTLD, specifically DLBCL, with combined brentuximab vedotin and third-party EBV-CTLs has been described in a case report ${ }^{[109]}$. EBVCTLs have also been combined with checkpoint therapy. Recent phase I/II trials have reported manageable toxicity profiles and promising anti-tumor activities of anti-PD-1 drugs (pembrolizumab, nivolumab, camrelizumab, and JS001) with/without chemotherapy in the treatment of recurrent/metastatic nasopharyngeal carcinoma ${ }^{[110-12]}$. While this approach is appealing, an anticipated limitation could be more rapid rejection of third-party CTLs and requires further clinical evaluation in a prospective setting.

\section{EBV-specific inhibitors}

There is potential future use of EBV-specific inhibitors, including inhibitors of EBNA1 and EBNA2 as well as heat-shock protein 90 (HSP90) inhibitors. EBNA1 is consistently expressed in EBV-positive PTLD, and it is responsible for the attachment of the viral episome to human chromosomes and facilitates its segregation during cell division ${ }^{[113]}$. EBNA1-specific inhibitors that block the DNA-binding domain of EBNA1 and inhibit tumor growth in vivo have shown therapeutic potential ${ }^{[13]}$. EBNA2 is the first viral protein to be expressed upon EBV infection, and it is a potent inducer of viral (LMP1 and LMP2A) and cellular (c-myc, IL-18 receptor, and others) protein ${ }^{[114]}$. EBNA2 inhibitors are therefore a potential therapeutic option for EBV-positive PTLD. HSP90 is induced in B cells early during EBV infection, expressed on the surface of EBV-transformed B cells, and upregulated on EBV-positive PTLD ${ }^{[115]}$. HSP90 inhibitors decrease EBNA-1 and $L M P 1$ expression and translation leading to inhibition of growth in preclinical models ${ }^{[15]}$. All of these inhibitors are currently being evaluated in preclinical and clinical trials, but none are approved for clinical use at this time.

\section{CONCLUSION}

Historically, management of PTLD has varied by recipient type (HCT vs. SOT), PTLD subtype, and treatment setting. There are practice differences based on whether patients are treated primarily by HCT or SOT transplant physicians, oncologists, or infectious disease specialists. Our understanding of risk stratification, treatment algorithms, and response will likely benefit from more uniform data collection and reporting as is currently being performed by some of the large registries for HCT and SOT recipients. Despite this landscape, there is increasing support for the use of single-agent rituximab as well as RIS as preemptive therapy for EBV viremia in high-risk patients, first-line therapy for PTLD in SOT recipients with risk-stratified sequential treatment, and second-line therapy in both HCT and SOT recipients with other treatments such as adoptive immunotherapy with EBV-CTLs. While the latter has been generally available only for those patients treated at selective sites or for patients willing and able to travel to such sites, this option is becoming more broadly available. A choice among therapies must take into consideration the aggressiveness of the PTLD, the expected time to response of individual therapies, and associated toxicities. Importantly, there is a clear need for uniformity in risk stratification of disease as well as in definitions of complete and partial responses and the timing of those assessments. Without more standardized approaches, it will be difficult to compare outcomes for the broadening array of therapeutic approaches. Furthermore, long-term studies are needed to evaluate toxicities and durability of responses to both chemotherapy and non-chemotherapy treatments such as CTLs. Overall, the future therapeutic perspective looks promising for PTLD with increasing availability of targeted chemotherapy and nonchemotherapy treatment options. 


\section{DECLARATIONS}

\section{Acknowledgements}

We thank Joseph Olechnowicz for editorial assistance.

\section{Authors' contributions}

Developed the concepts and wrote this review: Shahid S, Prockop SE

\section{Availability of data and materials}

Not applicable.

\section{Financial support and sponsorship}

We acknowledge support of the NCI Cancer Center Support Grant P30 CA008748.

\section{Conflicts of interest}

Prockop SE receives support through MSK for the conduct of sponsored trials from Atara Biotherapeutics, Jasper, and AlloVir. Advisory Board Neovii. Prockop SE is an inventor of IP licensed to Atara Biotherapeutics by MSK with her rights all assigned to MSK.

\section{Ethical approval and consent to participate}

Not applicable.

\section{Consent for publication}

Not applicable.

\section{Copyright}

(c) The Author(s) 2021.

\section{REFERENCES}

1. Samant H, Vaitla P, Kothadia JP. Post Transplant Lymphoproliferative Disorders. In: StatPearls [Internet]. Treasure Island (FL): StatPearls Publishing; 2021. PubMed

2. Weissmann DJ, Ferry JA, Harris NL, Louis DN, Delmonico F, Spiro I. Posttransplantation lymphoproliferative disorders in solid organ recipients are predominantly aggressive tumors of host origin. Am J Clin Pathol 1995;103:748-55. DOI PubMed

3. Jacobson CA, LaCasce AS. Lymphoma: risk and response after solid organ transplant. Oncology (Williston Park) 2010;24:936-44. PubMed

4. Murray RJ, Kurilla MG, Brooks JM, et al. Identification of target antigens for the human cytotoxic T cell response to Epstein-Barr virus (EBV): implications for the immune control of EBV-positive malignancies. J Exp Med 1992;176:157-68. DOI PubMed PMC

5. Hislop AD, Taylor GS, Sauce D, Rickinson AB. Cellular responses to viral infection in humans: lessons from Epstein-Barr virus. Annu Rev Immunol 2007;25:587-617. DOI PubMed

6. Prockop SE, Vatsayan A. Epstein-Barr virus lymphoproliferative disease after solid organ transplantation. Cytotherapy 2017;19:1270-83. DOI PubMed

7. Taylor AL, Bowles KM, Callaghan CJ, et al. Anthracycline-based chemotherapy as first-line treatment in adults with malignant posttransplant lymphoproliferative disorder after solid organ transplantation. Transplantation 2006;82:375-81. DOI PubMed

8. Trappe RU, Dierickx D, Zimmermann H, et al. Response to Rituximab induction is a predictive marker in B-cell post-transplant lymphoproliferative disorder and allows successful stratification into Rituximab or R-CHOP consolidation in an international, prospective, multicenter phase II trial. J Clin Oncol 2017;35:536-43. DOI PubMed

9. Styczynski J, Tridello G, Gil L, et al. Impact of donor Epstein-Barr virus serostatus on the incidence of graft-versus-host disease in patients with acute leukemia after hematopoietic stem-cell transplantation: a study from the acute leukemia and infectious diseases working parties of the european society for blood and marrow transplantation. J Clin Oncol 2016;34:2212-20. DOI PubMed

10. Ibrahim HA, Naresh KN. Posttransplant lymphoproliferative disorders. Adv Hematol 2012;2012:230173. DOI PubMed PMC

11. Opelz G, Daniel V, Naujokat C, Döhler B. Epidemiology of pretransplant EBV and CMV serostatus in relation to posttransplant nonHodgkin lymphoma. Transplantation 2009;88:962-7. DOI PubMed

12. Boubenider S, Hiesse C, Goupy C, Kriaa F, Marchand S, Charpentier B. Incidence and consequences of post-transplantation lymphoproliferative disorders. J Nephrol 1997;10:136-45. PubMed

13. Gupta D, Mendonca S, Chakraborty S, Chatterjee T. Post transplant lymphoproliferative disorder. Indian J Hematol Blood Transfus 2020;36:229-37. DOI PubMed PMC 
14. Petrara MR, Giunco S, Serraino D, Dolcetti R, De Rossi A. Post-transplant lymphoproliferative disorders: from epidemiology to pathogenesis-driven treatment. Cancer Lett 2015;369:37-44. DOI PubMed

15. Engels EA, Pfeiffer RM, Fraumeni JF Jr, et al. Spectrum of cancer risk among US solid organ transplant recipients. JAMA 2011;306:1891-901. DOI PubMed PMC

16. Dierickx D, Habermann TM. Post-transplantation lymphoproliferative disorders in adults. N Engl J Med 2018;378:549-62. DOI PubMed

17. Stojanova J, Caillard S, Rousseau A, Marquet P. Post-transplant lymphoproliferative disease (PTLD): pharmacological, virological and other determinants. Pharmacol Res 2011;63:1-7. DOI PubMed

18. Taylor AL, Marcus R, Bradley JA. Post-transplant lymphoproliferative disorders (PTLD) after solid organ transplantation. Crit Rev Oncol Hematol 2005;56:155-67. DOI PubMed

19. Trappe R, Oertel S, Leblond V, et al; German PTLD Study Group; European PTLD Network. Sequential treatment with rituximab followed by CHOP chemotherapy in adult B-cell post-transplant lymphoproliferative disorder (PTLD): the prospective international multicentre phase 2 PTLD-1 trial. Lancet Oncol 2012;13:196-206. DOI PubMed

20. Cheson BD, Fisher RI, Barrington SF, et al; Alliance; Australasian Leukaemia and Lymphoma Group; Eastern Cooperative Oncology Group; European Mantle Cell Lymphoma Consortium; Italian Lymphoma Foundation; European Organisation for Research; Treatment of Cancer/Dutch Hemato-Oncology Group; Grupo Español de Médula Ósea; German High-Grade Lymphoma Study Group; German Hodgkin's Study Group; Japanese Lymphorra Study Group; Lymphoma Study Association; NCIC Clinical Trials Group; Nordic Lymphoma Study Group; Southwest Oncology Group; United Kingdom National Cancer Research Institute. Recommendations for initial evaluation, staging, and response assessment of Hodgkin and non-Hodgkin lymphoma: the Lugano classification. J Clin Oncol 2014;32:3059-68. DOI PubMed PMC

21. Al-Mansour Z, Nelson BP, Evens AM. Post-transplant lymphoproliferative disease (PTLD): risk factors, diagnosis, and current treatment strategies. Curr Hematol Malig Rep 2013;8:173-83. DOI PubMed PMC

22. Caillard S, Porcher R, Provot F, et al. Post-transplantation lymphoproliferative disorder after kidney transplantation: report of a nationwide French registry and the development of a new prognostic score. J Clin Oncol 2013;31:1302-9. DOI PubMed

23. Trappe RU, Choquet S, Dierickx D, et al; German PTLD Study Group and the European PTLD Network. International prognostic index, type of transplant and response to rituximab are key parameters to tailor treatment in adults with CD20-positive B cell PTLD: clues from the PTLD-1 trial. Am J Transplant 2015;15:1091-100. DOI PubMed

24. Dierickx D, Tousseyn T, Morscio J, Fieuws S, Verhoef G. Validation of prognostic scores in post-transplantation lymphoproliferative disorders. J Clin Oncol 2013;31:3443-4. DOI PubMed

25. Podoltsev N, Zhang B, Yao X, Bustillo I, Deng Y, Cooper DL. Chemoimmunotherapy and withdrawal of immunosuppression for monomorphic posttransplant lymphoproliferative disorders. Clin Lymphoma Myeloma Leuk 2013;13:716-20. DOI PubMed PMC

26. Styczynski J, Gil L, Tridello G, et al; Infectious Diseases Working Party of the European Group for Blood and Marrow Transplantation. Response to rituximab-based therapy and risk factor analysis in Epstein Barr Virus-related lymphoproliferative disorder after hematopoietic stem cell transplant in children and adults: a study from the Infectious Diseases Working Party of the European Group for Blood and Marrow Transplantation. Clin Infect Dis 2013;57:794-802. DOI PubMed

27. Prockop S, Doubrovina E, Suser S, et al. Off-the-shelf EBV-specific T cell immunotherapy for rituximab-refractory EBV-associated lymphoma following transplantation. J Clin Invest 2020;130:733-47. DOI PubMed PMC

28. Reshef R, Vardhanabhuti S, Luskin MR, et al. Reduction of immunosuppression as initial therapy for posttransplantation lymphoproliferative disorder. Am J Transplant 2011;11:336-47. DOI PubMed PMC

29. Gu Z, Cai B, Yuan L, et al. Successful treatment of polymorphic post-transplant lymphoproliferative disorder after allo-HSCT with reduction of immunosuppression. Int J Clin Exp Med 2014;7:1904-9. PubMed PMC

30. Starzl TE, Nalesnik MA, Porter KA, et al. Reversibility of lymphomas and lymphoproliferative lesions developing under cyclosporinsteroid therapy. Lancet 1984;1:583-7. DOI PubMed PMC

31. Fox CP, Burns D, Parker AN, et al. EBV-associated post-transplant lymphoproliferative disorder following in vivo T-cell-depleted allogeneic transplantation: clinical features, viral load correlates and prognostic factors in the rituximab era. Bone Marrow Transplant 2014;49:280-6. DOI PubMed

32. Ocheni S, Kroeger N, Zabelina T, et al. EBV reactivation and post transplant lymphoproliferative disorders following allogeneic SCT. Bone Marrow Transplant 2008;42:181-6. DOI PubMed

33. Styczynski J, Einsele H, Gil L, Ljungman P. Outcome of treatment of Epstein-Barr virus-related post-transplant lymphoproliferative disorder in hematopoietic stem cell recipients: a comprehensive review of reported cases. Transpl Infect Dis 2009;11:383-92. DOI PubMed

34. Tsai DE, Hardy CL, Tomaszewski JE, et al. Reduction in immunosuppression as initial therapy for posttransplant lymphoproliferative disorder: analysis of prognostic variables and long-term follow-up of 42 adult patients. Transplantation 2001;71:1076-88. DOI PubMed

35. Swinnen LJ, LeBlanc M, Grogan TM, et al. Prospective study of sequential reduction in immunosuppression, interferon alpha-2B, and chemotherapy for posttransplantation lymphoproliferative disorder. Transplantation 2008;86:215-22. DOI PubMed PMC

36. Elstrom RL, Andreadis C, Aqui NA, et al. Treatment of PTLD with rituximab or chemotherapy. Am J Transplant 2006;6:569-76. DOI PubMed

37. Ghobrial IM, Habermann TM, Maurer MJ, et al. Prognostic analysis for survival in adult solid organ transplant recipients with posttransplantation lymphoproliferative disorders. J Clin Oncol 2005;23:7574-82. DOI PubMed

38. Swinnen LJ, Mullen GM, Carr TJ, Costanzo MR, Fisher RI. Aggressive treatment for postcardiac transplant lymphoproliferation. 
Blood 1995;86:3333-40. PubMed

39. Knight JS, Tsodikov A, Cibrik DM, Ross CW, Kaminski MS, Blayney DW. Lymphoma after solid organ transplantation: risk, response to therapy, and survival at a transplantation center. J Clin Oncol 2009;27:3354-62. DOI PubMed

40. Jagadeesh D, Woda BA, Draper J, Evens AM. Post transplant lymphoproliferative disorders: risk, classification, and therapeutic recommendations. Curr Treat Options Oncol 2012;13:122-36. DOI PubMed

41. Oton $\mathrm{AB}$, Wang $\mathrm{H}$, Leleu $\mathrm{X}$, et al. Clinical and pathological prognostic markers for survival in adult patients with post-transplant lymphoproliferative disorders in solid transplant. Leuk Lymphoma 2008;49:1738-44. DOI PubMed

42. Caillard S, Dharnidharka V, Agodoa L, Bohen E, Abbott K. Posttransplant lymphoproliferative disorders after renal transplantation in the United States in era of modern immunosuppression. Transplantation 2005;80:1233-43. DOI PubMed

43. Schober T, Framke T, Kreipe H, et al. Characteristics of early and late PTLD development in pediatric solid organ transplant recipients. Transplantation 2013;95:240-6. DOI PubMed

44. Orjuela MA, Alobeid B, Liu X, et al. CD20 expression predicts survival in paediatric post-transplant lymphoproliferative disease (PTLD) following solid organ transplantation. Br J Haematol 2011;152:733-42. DOI PubMed

45. Maecker B, Jack T, Zimmermann M, et al. CNS or bone marrow involvement as risk factors for poor survival in post-transplantation lymphoproliferative disorders in children after solid organ transplantation. J Clin Oncol 2007;25:4902-8. DOI PubMed

46. Nepomuceno RR, Balatoni CE, Natkunam Y, Snow AL, Krams SM, Martinez OM. Rapamycin inhibits the interleukin 10 signal transduction pathway and the growth of Epstein Barr virus B-cell lymphomas. Cancer Res 2003;63:4472-80. PubMed

47. Cullis B, D'Souza R, McCullagh P, et al. Sirolimus-induced remission of posttransplantation lymphoproliferative disorder. Am J Kidney Dis 2006;47:e67-72. DOI PubMed

48. Boratyńska M, Wątorek E, Smolska D, Patrzałek D, Klinger M. Anticancer effect of sirolimus in renal allograft recipients with de novo malignancies. Transplant Proc 2007;39:2736-9. DOI PubMed

49. Salles G, Barrett M, Foà R, et al. Rituximab in B-cell hematologic malignancies: a review of 20 years of clinical experience. $A d v$ Ther 2017;34:2232-73. DOI PubMed PMC

50. Tomblyn M, Chiller T, Einsele H, et al; Center for International Blood and Marrow Research; National Marrow Donor program; European Blood and MarrowTransplant Group; American Society of Blood and Marrow Transplantation; Canadian Blood and Marrow Transplant Group; Infectious Diseases Society of America; Society for Healthcare Epidemiology of America; Association of Medical Microbiology and Infectious Disease Canada; Centers for Disease Control and Prevention. Guidelines for preventing infectious complications among hematopoietic cell transplantation recipients: a global perspective. Biol Blood Marrow Transplant 2009;15:1143-238. DOI PubMed PMC

51. Styczynski J, van der Velden W, Fox CP, et al; Sixth European Conference on Infections in Leukemia; a joint venture of the Infectious Diseases Working Party of the European Society of Blood and Marrow Transplantation (EBMT-IDWP); the Infectious Diseases Group of the European Organization for Research and Treatment of Cancer (EORTC-IDG); the International Immunocompromised Host Society (ICHS) and the European Leukemia Net (ELN). Management of Epstein-Barr Virus infections and post-transplant lymphoproliferative disorders in patients after allogeneic hematopoietic stem cell transplantation: Sixth European Conference on Infections in Leukemia (ECIL-6) guidelines. Haematologica 2016;101:803-11. DOI PubMed PMC

52. Expert Group on Renal Transplantation. European best practice guidelines for renal transplantation. Section IV: Long-term management of the transplant recipient. IV.6.1. Cancer risk after renal transplantation. Post-transplant lymphoproliferative disease (PTLD): prevention and treatment. Nephrol Dial Transplant 2002;17 Suppl 4:31-3, 5. DOI PubMed

53. Yang J, Tao Q, Flinn IW, et al. Characterization of Epstein-Barr virus-infected B cells in patients with posttransplantation lymphoproliferative disease: disappearance after rituximab therapy does not predict clinical response. Blood 2000;96:4055-63. PubMed

54. Choquet S, Leblond V, Herbrecht R, et al. Efficacy and safety of rituximab in B-cell post-transplantation lymphoproliferative disorders: results of a prospective multicenter phase 2 study. Blood 2006;107:3053-7. DOI PubMed

55. Choquet S, Oertel S, LeBlond V, et al. Rituximab in the management of post-transplantation lymphoproliferative disorder after solid organ transplantation: proceed with caution. Ann Hematol 2007;86:599-607. DOI PubMed

56. González-Barca E, Domingo-Domenech E, Capote FJ, et al; GEL/TAMO (Grupo Español de Linfomas); GELCAB (Grupo para el Estudio de los Linfomas Catalano-Balear); GOTEL (Grupo Oncológico para el Tratamiento y Estudio de los Linfomas). Prospective phase II trial of extended treatment with rituximab in patients with B-cell post-transplant lymphoproliferative disease. Haematologica 2007;92:1489-94. DOI PubMed

57. Teeling JL, Mackus WJ, Wiegman LJ, et al. The biological activity of human CD20 monoclonal antibodies is linked to unique epitopes on CD20. J Immunol 2006;177:362-71. DOI PubMed

58. Herter S, Herting F, Mundigl O, et al. Preclinical activity of the type II CD20 antibody GA101 (obinutuzumab) compared with rituximab and ofatumumab in vitro and in xenograft models. Mol Cancer Ther 2013;12:2031-42. DOI PubMed

59. Coiffier B, Lepretre S, Pedersen LM, et al. Safety and efficacy of ofatumumab, a fully human monoclonal anti-CD20 antibody, in patients with relapsed or refractory B-cell chronic lymphocytic leukemia: a phase 1-2 study. Blood 2008;111:1094-100. DOI PubMed

60. Ghione P, Joffe E, De Paola N, et al. Alternative anti-CD20 antibody versus desensitization for lymphoma patients with drug hypersensitivity reactions requiring discontinuation of rituximab, obinutuzumab, or ofatumumab. J Clin Oncol 2020;38:8062. DOI

61. Hamed R, Bazarbachi AH, Mohty M. Epstein-Barr virus-related post-transplant lymphoproliferative disease (EBV-PTLD) in the setting of allogeneic stem cell transplantation: a comprehensive review from pathogenesis to forthcoming treatment modalities. Bone Marrow Transplant 2020;55:25-39. DOI PubMed 
62. Gross TG, Orjuela MA, Perkins SL, et al. Low-dose chemotherapy and rituximab for posttransplant lymphoproliferative disease (PTLD): a Children's Oncology Group Report. Am J Transplant 2012;12:3069-75. DOI PubMed PMC

63. Rummel MJ, Al-Batran SE, Kim SZ, et al. Bendamustine plus rituximab is effective and has a favorable toxicity profile in the treatment of mantle cell and low-grade non-Hodgkin's lymphoma. J Clin Oncol 2005;23:3383-9. DOI PubMed

64. Duval A, Raphael M, Brennetot C, et al. The mutator pathway is a feature of immunodeficiency-related lymphomas. Proc Natl Acad Sci U S A 2004;101:5002-7. DOI PubMed PMC

65. Le DT, Uram JN, Wang H, et al. PD-1 Blockade in Tumors with Mismatch-Repair Deficiency. N Engl J Med 2015;372:2509-20. DOI PubMed PMC

66. Kinch A, Sundström C, Baecklund E, Backlin C, Molin D, Enblad G. Expression of PD-1, PD-L1, and PD-L2 in posttransplant lymphoproliferative disorder after solid organ transplantation. Leuk Lymphoma 2019;60:376-84. DOI PubMed

67. Ferreiro JF, Morscio J, Dierickx D, et al. EBV-positive and EBV-negative posttransplant diffuse large B cell lymphomas have distinct genomic and transcriptomic features. Am J Transplant 2016;16:414-25. DOI PubMed

68. Veloza L, Teixido C, Castrejon N, et al. Clinicopathological evaluation of the programmed cell death 1 (PD1)/programmed cell death-ligand 1 (PD-L1) axis in post-transplant lymphoproliferative disorders: association with Epstein-Barr virus, PD-L1 copy number alterations, and outcome. Histopathology 2019;75:799-812. DOI PubMed

69. Kassa C, Reményi P, Sinkó J, Kállay K, Kertész G, Kriván G. Successful nivolumab therapy in an allogeneic stem cell transplant child with post-transplant lymphoproliferative disorder. Pediatr Transplant 2018;22:e13302. DOI PubMed

70. Volk V, Theobald SJ, Danisch S, et al. PD-1 blockade aggravates Epstein-Barr Virus $(+)$ post-transplant lymphoproliferative disorder in humanized mice resulting in central nervous system involvement and CD4(+) T cell dysregulations. Front Oncol 2020;10:614876. DOI PubMed PMC

71. Shannon-Lowe C, Rickinson A. The global landscape of EBV-associated tumors. Front Oncol 2019;9:713. DOI PubMed PMC

72. Tse E, Kwong YL. Epstein Barr virus-associated lymphoproliferative diseases: the virus as a therapeutic target. Exp Mol Med 2015;47:e136. DOI PubMed PMC

73. Thompson MP, Kurzrock R. Epstein-Barr virus and cancer. Clin Cancer Res 2004;10:803-21. DOI PubMed

74. Ghosh SK, Perrine SP, Williams RM, Faller DV. Histone deacetylase inhibitors are potent inducers of gene expression in latent EBV and sensitize lymphoma cells to nucleoside antiviral agents. Blood 2012;119:1008-17. DOI PubMed PMC

75. Anisimová E, Prachová K, Roubal J, Vonka V. Effects of n-butyrate and phorbol ester (TPA) on induction of Epstein-Barr virus antigens and cell differentiation. Arch Virol 1984;81:223-37. DOI PubMed

76. Saemundsen AK, Kallin B, Klein G. Effect of n-butyrate on cellular and viral DNA synthesis in cells latently infected with EpsteinBarr virus. Virology 1980;107:557-61. DOI PubMed

77. Mentzer SJ, Fingeroth J, Reilly JJ, Perrine SP, Faller DV. Arginine butyrate-induced susceptibility to ganciclovir in an Epstein-Barrvirus-associated lymphoma. Blood Cells Mol Dis 1998;24:114-23. DOI PubMed

78. Perrine SP, Hermine O, Small T, et al. A phase 1/2 trial of arginine butyrate and ganciclovir in patients with Epstein-Barr virusassociated lymphoid malignancies. Blood 2007;109:2571-8. DOI PubMed PMC

79. Sutrave G, Gottlieb DJ. Adoptive cell therapies for posttransplant infections. Curr Opin Oncol 2019;31:574-90. DOI PubMed

80. Papadopoulos EB, Ladanyi M, Emanuel D, et al. Infusions of donor leukocytes to treat Epstein-Barr Virus-associated lymphoproliferative disorders after allogeneic bone marrow transplantation. N Engl J Med 1994;330:1185-91. DOI PubMed

81. Gottschalk S, Rooney CM, Heslop HE. Post-transplant lymphoproliferative disorders. Annu Rev Med 2005;56:29-44. DOI PubMed

82. Slobod KS, Benaim E, Woodruff L, et al. T cell immunotherapeutic populations control viral infections in bone marrow transplant recipients. Immunol Res 2001;24:289-301. DOI PubMed

83. Gustafsson A, Levitsky V, Zou JZ, et al. Epstein-Barr virus (EBV) load in bone marrow transplant recipients at risk to develop posttransplant lymphoproliferative disease: prophylactic infusion of EBV-specific cytotoxic T cells. Blood 2000;95:807-14. PubMed

84. Comoli P, Basso S, Zecca M, et al. Preemptive therapy of EBV-related lymphoproliferative disease after pediatric haploidentical stem cell transplantation. Am J Transplant 2007;7:1648-55. DOI PubMed

85. O'Reilly RJ, Doubrovina E, Trivedi D, Hasan A, Kollen W, Koehne G. Adoptive transfer of antigen-specific T-cells of donor type for immunotherapy of viral infections following allogeneic hematopoietic cell transplants. Immunol Res 2007;38:237-50. DOI PubMed

86. Comoli P, Labirio M, Basso S, et al. Infusion of autologous Epstein-Barr virus (EBV)-specific cytotoxic T cells for prevention of EBV-related lymphoproliferative disorder in solid organ transplant recipients with evidence of active virus replication. Blood 2002;99:2592-8. DOI PubMed

87. Khanna R, Bell S, Sherritt M, et al. Activation and adoptive transfer of Epstein-Barr virus-specific cytotoxic T cells in solid organ transplant patients with posttransplant lymphoproliferative disease. Proc Natl Acad Sci U S A 1999;96:10391-6. DOI PubMed PMC

88. Savoldo B, Goss JA, Hammer MM, et al. Treatment of solid organ transplant recipients with autologous Epstein Barr virus-specific cytotoxic T lymphocytes (CTLs). Blood 2006;108:2942-9. DOI PubMed PMC

89. Pakakasama S, Eames GM, Morriss MC, et al. Treatment of Epstein-Barr virus lymphoproliferative disease after hematopoietic stemcell transplantation with hydroxyurea and cytotoxic T-cell lymphocytes. Transplantation 2004;78:755-7. DOI PubMed

90. Haque T, Wilkie GM, Taylor C, et al. Treatment of Epstein-Barr-virus-positive post-transplantation lymphoproliferative disease with partly HLA-matched allogeneic cytotoxic T cells. Lancet 2002;360:436-42. DOI PubMed

91. Haque T, Wilkie GM, Jones MM, et al. Allogeneic cytotoxic T-cell therapy for EBV-positive posttransplantation lymphoproliferative disease: results of a phase 2 multicenter clinical trial. Blood 2007;110:1123-31. DOI PubMed

92. Gandhi MK, Wilkie GM, Dua U, et al. Immunity, homing and efficacy of allogeneic adoptive immunotherapy for posttransplant lymphoproliferative disorders. Am J Transplant 2007;7:1293-9. DOI PubMed 
93. Sun Q, Burton R, Reddy V, Lucas KG. Safety of allogeneic Epstein-Barr virus (EBV)-specific cytotoxic T lymphocytes for patients with refractory EBV-related lymphoma. Br J Haematol 2002;118:799-808. DOI PubMed

94. Chiou FK, Beath SV, Wilkie GM, Vickers MA, Morland B, Gupte GL. Cytotoxic T-lymphocyte therapy for post-transplant lymphoproliferative disorder after solid organ transplantation in children. Pediatr Transplant 2018:22. DOI PubMed

95. Tzannou I, Papadopoulou A, Naik S, Leung K, Martinez CA, Ramos CA, et al. Off-the-shelf virus-specific T cells to treat BK virus, human herpesvirus 6, cytomegalovirus, Epstein-Barr virus, and adenovirus infections after allogeneic hematopoietic stem-cell transplantation. J Clin Oncol 2017;35:3547-57. DOI PubMed PMC

96. Papadopoulou A, Gerdemann U, Katari UL, et al. Activity of broad-spectrum T cells as treatment for AdV, EBV, CMV, BKV, and HHV6 infections after HSCT. Sci Transl Med 2014;6:242ra83. DOI PubMed PMC

97. Heslop HE, Ng CYC, Li C, et al. Long-term restoration of immunity against Epstein-Barr virus infection by adoptive transfer of gene-modified virus-specific T lymphocytes. Nat Med 1996;2:551-5. DOI PubMed

98. Bollard CM, Gottschalk S, Torrano V, et al. Sustained complete responses in patients with lymphoma receiving autologous cytotoxic T lymphocytes targeting Epstein-Barr virus latent membrane proteins. J Clin Oncol 2014;32:798-808. DOI PubMed PMC

99. Doubrovina E, Oflaz-Sozmen B, Prockop SE, et al. Adoptive immunotherapy with unselected or EBV-specific T cells for biopsyproven EBV+ lymphomas after allogeneic hematopoietic cell transplantation. Blood 2012;119:2644-56. DOI PubMed PMC

100. Koehne G, Doubrovin M, Doubrovina E, et al. Serial in vivo imaging of the targeted migration of human HSV-TK-transduced antigen-specific lymphocytes. Nat Biotechnol 2003;21:405-13. DOI PubMed

101. Gerdemann U, Keirnan JM, Katari UL, et al. Rapidly generated multivirus-specific cytotoxic T lymphocytes for the prophylaxis and treatment of viral infections. Mol Ther 2012;20:1622-32. DOI PubMed PMC

102. Gottschalk S, Ng CY, Perez M, et al. An Epstein-Barr virus deletion mutant associated with fatal lymphoproliferative disease unresponsive to therapy with virus-specific CTLs. Blood 2001;97:835-43. DOI PubMed

103. Dalton T, Doubrovina E, Pankov D, et al. Epigenetic reprogramming sensitizes immunologically silent EBV+ lymphomas to virusdirected immunotherapy. Blood 2020;135:1870-81. DOI PubMed PMC

104. Cho SG, Kim N, Sohn HJ, et al. Long-term outcome of extranodal NK/T cell lymphoma patients treated with postremission therapy using EBV LMP1 and LMP2a-specific CTLs. Mol Ther 2015;23:1401-9. DOI PubMed PMC

105. Gottschalk S, Edwards OL, Sili U, et al. Generating CTLs against the subdominant Epstein-Barr virus LMP1 antigen for the adoptive immunotherapy of EBV-associated malignancies. Blood 2003;101:1905-12. DOI PubMed

106. Sieber M, Baumgrass R. Novel inhibitors of the calcineurin/NFATc hub - alternatives to CsA and FK506? Cell Commun Signal 2009;7:25. DOI PubMed PMC

107. Brewin J, Mancao C, Straathof K, et al. Generation of EBV-specific cytotoxic T cells that are resistant to calcineurin inhibitors for the treatment of posttransplantation lymphoproliferative disease. Blood 2009;114:4792-803. DOI PubMed

108. Reik A, Zhou Y, Wagner J, et al. Zinc finger nucleases targeting the glucocorticoid receptor allow IL-13 zetakine transgenic CTLs to kill glioblastoma cells in vivo in the presence of immunosuppressing glucocorticoids. Cancer Res 2008;68:2557.

109. Mika T, Strate K, Ladigan S, et al. Refractory Epstein-Barr Virus (EBV)-related post-transplant lymphoproliferative disease: cure by combined brentuximab vedotin and allogeneic EBV-specific T-lymphocytes. Front Med (Lausanne) 2019;6:295. DOI PubMed $\mathrm{PMC}$

110. Hsu C, Lee SH, Ejadi S, et al. Safety and antitumor activity of pembrolizumab in patients with programmed death-ligand 1-positive nasopharyngeal carcinoma: results of the KEYNOTE-028 Study. J Clin Oncol 2017;35:4050-6. DOI PubMed

111. Ma BBY, Lim WT, Goh BC, et al. Antitumor activity of nivolumab in recurrent and metastatic nasopharyngeal carcinoma: an international, multicenter study of the mayo clinic phase 2 consortium (NCI-9742). J Clin Oncol 2018;36:1412-8. DOI PubMed PMC

112. Fang W, Yang Y, Ma Y, et al. Camrelizumab (SHR-1210) alone or in combination with gemcitabine plus cisplatin for nasopharyngeal carcinoma: results from two single-arm, phase 1 trials. Lancet Oncol 2018;19:1338-50. DOI PubMed

113. Jiang L, Xie C, Lung HL, et al. EBNA1-targeted inhibitors: novel approaches for the treatment of Epstein-Barr virus-associated cancers. Theranostics 2018;8:5307-19. DOI PubMed PMC

114. Maier S, Staffler G, Hartmann A, et al. Cellular target genes of Epstein-Barr virus nuclear antigen 2. J Virol 2006;80:9761-71. DOI PubMed PMC

115. Shatzer A, Ali MA, Chavez M, et al. Ganetespib, an HSP90 inhibitor, kills Epstein-Barr virus (EBV)-infected B and T cells and reduces the percentage of EBV-infected cells in the blood. Leuk Lymphoma 2017;58:923-31. DOI PubMed PMC

116. Rooney CM, Smith CA, Ng CY, et al. Use of gene-modified virus-specific T lymphocytes to control Epstein-Barr-virus-related lymphoproliferation. Lancet 1995;345:9-13. DOI PubMed

117. Rooney CM, Smith CA, Ng CY, et al. Infusion of cytotoxic T cells for the prevention and treatment of Epstein-Barr virus-induced lymphoma in allogeneic transplant recipients. Blood 1998;92:1549-55. PubMed

118. Heslop HE, Slobod KS, Pule MA, et al. Long-term outcome of EBV-specific T-cell infusions to prevent or treat EBV-related lymphoproliferative disease in transplant recipients. Blood 2010;115:925-35. DOI PubMed PMC

119. Lucas KG, Small TN, Heller G, Dupont B, O'Reilly RJ. The development of cellular immunity to Epstein-Barr virus after allogeneic bone marrow transplantation. Blood 1996;87:2594-603. PubMed

120. Imashuku S, Naya M, Yamori M, et al. Bone marrow transplatation for Epstein-Barr virus-related clonal $\mathrm{T}$ cell proliferation associated with hemophagocytosis. Bone Marrow Transplant 1997;19:1059-60. DOI PubMed

121. Comoli P, Basso S, Labirio M, Baldanti F, Maccario R, Locatelli F. T cell therapy of Epstein-Barr virus and adenovirus infections after hemopoietic stem cell transplant. Blood Cells Mol Dis 2008;40:68-70. DOI PubMed 
122. Moosmann A, Bigalke I, Tischer J, et al. Effective and long-term control of EBV PTLD after transfer of peptide-selected T cells. Blood 2010;115:2960-70. DOI PubMed

123. Icheva V, Kayser S, Wolff D, et al. Adoptive transfer of epstein-barr virus (EBV) nuclear antigen 1-specific $\mathrm{T}$ cells as treatment for EBV reactivation and lymphoproliferative disorders after allogeneic stem-cell transplantation. J Clin Oncol 2012;31:39-48. DOI PubMed

124. Gerdemann U, Katari UL, Papadopoulou A, et al. Safety and clinical efficacy of rapidly-generated trivirus-directed T cells as treatment for adenovirus, EBV, and CMV infections after allogeneic hematopoietic stem cell transplant. Mol Ther 2013;21:2113-21. DOI PubMed PMC

125. Lucas KG, Salzman D, Garcia A, Sun Q. Adoptive immunotherapy with allogeneic Epstein-Barr virus (EBV)-specific cytotoxic Tlymphocytes for recurrent, EBV-positive Hodgkin disease. Cancer 2004;100:1892-901. DOI PubMed

126. Leen AM, Bollard CM, Mendizabal AM, et al. Multicenter study of banked third-party virus-specific T cells to treat severe viral infections after hematopoietic stem cell transplantation. Blood 2013;121:5113-23. DOI PubMed PMC

127. Gallot G, Vollant S, Saïagh S, et al. T-cell therapy using a bank of EBV-specific cytotoxic T cells: lessons from a phase I/II feasibility and safety study. J Immunother 2014;37:170-9. DOI PubMed

128. Vickers MA, Wilkie GM, Robinson N, et al. Establishment and operation of a Good Manufacturing Practice-compliant allogeneic Epstein-Barr virus (EBV)-specific cytotoxic cell bank for the treatment of EBV-associated lymphoproliferative disease. $\mathrm{Br} J$ Haematol 2014;167:402-10. DOI PubMed PMC

129. Alonso L, Perez A, Benitez MI, et al. Adoptive immunotherapy with virus specific T cell: experience of 2 Spanish cell-therapy laboratories. Bone Marrow Transplant 2019;53:P089. 